\title{
Gene trap lines identify Arabidopsis genes expressed in stomatal guard cells
}

\author{
Massimo Galbiati ${ }^{1,}{ }^{*}$, Laura Simoni ${ }^{1}$, Giulio Pavesi ${ }^{1}$, Eleonora Cominelli ${ }^{1}$, Priscilla Francia ${ }^{1}$, Alain Vavasseur ${ }^{2}$, Timothy Nelson ${ }^{3}$, \\ Michael Bevan ${ }^{4}$ and Chiara Tonelli ${ }^{1}$ \\ ${ }^{1}$ Dipartimento di Scienze Biomolecolari e Biotecnologie, Università degli Studi di Milano, Via Celoria 26, 20 133 Milano, Italy, \\ ${ }^{2}$ Commissariat à I'Energie Atomique, Direction des Sciences du Vivant, Laboratoire des Echanges Membranaires et \\ Signalisation, F-13 108 St Paul lez Durance Cedex, France, \\ ${ }^{3}$ Department of Molecular Cellular and Developmental Biology, Yale University, New Haven, CT 06 520-8140, USA, and \\ ${ }^{4}$ Department of Cell and Developmental Biology, John Innes Centre, Norwich NR4 7UH, UK
}

Received 9 August 2007; revised 18 October 2007; accepted 30 October 2007.

*For correspondence (fax +39025031 5044; e-mail massimo.galbiati@unimi.it).

\begin{abstract}
Summary
We employed a gene trap approach to identify genes expressed in stomatal guard cells of Arabidopsis thaliana. We examined patterns of reporter gene expression in approximately 20000 gene trap lines, and recovered five lines with exclusive or preferential expression in stomata. The screen yielded two insertions in annotated genes, encoding the CYTOCHROME P450 86A2 (CYP86A2) mono-oxygenase, and the PLEIOTROPIC DRUG RESISTANCE 3 (AtPDR3) transporter. Expression of the trapped genes in guard cells was confirmed by RT-PCR experiments in purified stomata. Examination of homozygous mutant lines revealed that abscisic acid (ABA)induced stomatal closure was impaired in the atpdr3 mutant. In three lines, insertions occurred outside transcribed units. Expression analysis of the genes surrounding the trapping inserts identified two genes selectively expressed in guard cells, corresponding to a PP2C PROTEIN PHOSPHATASE and an unknown expressed protein gene. Statistical analyses of the chromosomal regions tagged by the gene trap insertions revealed an over-represented [A/T]AAAG motif, previously described as an essential cis-active element for gene expression in stomata. The lines described in this work identify novel genes involved in the modulation of stomatal activity, provide useful markers for the study of developmental pathways in guard cells, and are a valuable source of guard cell-specific promoters.
\end{abstract}

Keywords: guard cell, gene trap, laser capture microdissection, cis-acting elements, Arabidopsis thaliana.

Introduction

Land plants lose over $95 \%$ of their water via transpiration through stomatal pores, distributed on the surface of leaves and stems. Opening and closing of the pore is mediated by turgor-driven volume changes in two surrounding guard cells. These highly specialized cells integrate internal signals and environmental stimuli to modulate stomatal aperture, ensuring the influx of $\mathrm{CO}_{2}$ for photosynthesis and limiting water loss by transpiration (MacRobbie, 1998). Engineering of stomatal activity, in mutant or transgenic plants, is an attractive approach to reduce the water requirements of crops and to enhance productivity under stress conditions (Schroeder et al., 2001). Evidence indicates that both disruption of negative regulators of guardcell responses and constitutive expression of positive regulators lead to enhanced stomatal closure and reduced water loss during drought (Gosti et al., 1999; Klein et al., 2003; Pei et al., 1998). However, most genes that modulate stomatal aperture are also expressed in other tissues and control several yield parameters (Schroeder et al., 2001). Genetic manipulation of stomatal responses requires the use of guard cell-specific promoters, or the identification of guard cell-specific mutants, to avoid undesirable sideeffects on plant growth and productivity. Putative guard cell-specific genes have been identified in a microarray survey of gene expression in leaf tissues (Leonhardt et al., 2004). This approach allowed analysis of a very large set of genes, but expression was only examined in guard cells and mesophyll cells. Further extensive efforts are required Journal compilation ๔ 2008 Blackwell Publishing Ltd 
to determine whether the selected genes are also active in other plant tissues.

We exploited a gene-trapping strategy as a direct method to identify candidate guard cell-specific genes. Gene trap lines, in which endogenous proteins are fused to reporter markers, can reveal the pattern of gene expression within individual cells in complex tissues, with no need for destructive manipulation of the plant material to isolate cell types (Sundaresan et al., 1995). Most importantly, gene trap insertions provide information on gene function, as they often disrupt the tagged gene and give rise to mutant phenotypes (Springer, 2000). In Arabidopsis, large-scale trapping screens have been successfully employed to identify genes expressed in restricted subdomains of floral organs (Nakayama et al., 2005), in seed tissues (Stangeland et al., 2003), and in various cell types of the vascular system (Nagawa et al., 2006).

We examined the expression pattern of the $\beta$-glucoronidase (GUS) reporter gene in approximately 20000 gene trap lines generated by the Exon Trapping Insert Consortium (EXOTIC, http://www.jic.bbsrc.ac.uk/hosting/exotic/mainframeset.htm). We identified five lines in which the reporter was exclusively or preferentially expressed in guard cells. Here we report the developmental patterns of GUS activity, identification of the chromosomal insertion sites of the gene trapper, and the expression profiles of the trapped genes in purified guard cells. Bioinformatic analyses revealed the presence of putative guard cell-specific cis-acting elements, defined as clusters of [A/T]AAAG motifs, in the regulatory regions of most of the genes that were upregulated in guard cells. Finally, examination of the five lines for unusual stomatal phenotypes identified one mutation affecting guard-cell responses to ABA. These results emphasize the high spatial resolution provided by gene trap screens, and validate their use for the identification of cell-specific genes and mutations.

\section{Results}

\section{Screening of the EXOTIC gene trap lines}

A large population of gene trap insertion lines has been generated in Arabidopsis by the EXOTIC project. Insertions were produced using the $A c / D s$-based system developed by R. Martienssen and colleagues (Sundaresan et al., 1995). EXOTIC lines carry a modified Ds transposable element $(D s G)$ containing the GUS reporter gene, flanked by a triple splice acceptor site and an intron, and the Nptll gene, conferring kanamycin resistance (Figure S1). Insertion of the DsG element inside a coding region results in production of a fusion protein consisting of two domains: a partial wild-type protein at the $\mathrm{N}$-terminus, and the full-length GUS protein at the C-terminus. Insertions in the sense orientation result in GUS activity
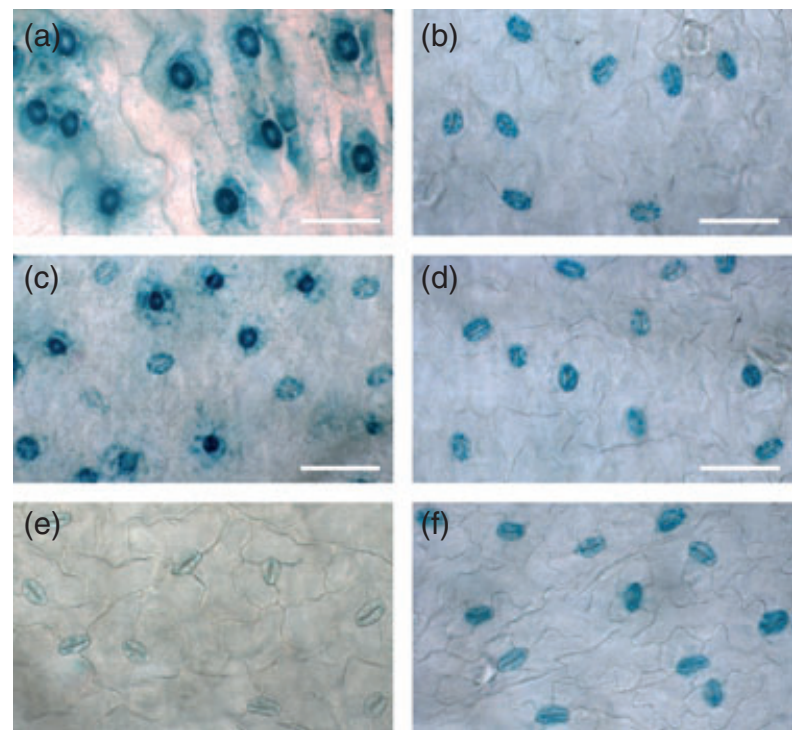

Figure 1. Guard cell-specific GUS expression in the EXOTIC lines. (a) GT1345, (b) GT116224, (c) GT100789, (d) GT106424, (e, f) GT105628. Rosette leaves from 15-day-old plants were incubated in the staining solution for $6 \mathrm{~h}(\mathrm{a}), 24 \mathrm{~h}(\mathrm{~b}-\mathrm{e})$ or $60 \mathrm{~h}$ (f). Scale bars represent $50 \mu \mathrm{m}$.

that mimics the normal expression pattern of the tagged gene.

To identify Arabidopsis genes expressed in stomata, we searched the EXOTIC lines for guard cell-specific activation of the GUS reporter. $F_{3}$ seeds from individual lines were germinated under kanamycin selection, and the histochemical localization of GUS expression was analysed in young rosette leaves from ten antibiotic-resistant plants. In total, we recovered five lines with specific GUS expression in stomata (Figure 1). Leaves from line GT1345 showed strong activity of the reporter in guard cells after $6 \mathrm{~h}$ of incubation in the staining solution, with less intense and diffuse signals in the surrounding pavement cells (Figure 1a). Leaves from lines GT116224, GT100789 and GT106424 exhibited guard cell-specific GUS signals after $24 \mathrm{~h}$ of incubation (Figure 1bd). GT100789 leaves displayed stronger activity in smaller stomata, suggesting that expression of the tagged gene may be developmentally regulated (Figure 1c). After a $24 \mathrm{~h}$ incubation, GT105628 leaves showed specific but faint GUS signals in guard cells (Figure 1e). We observed clear expression of the reporter only after $60 \mathrm{~h}$ of staining, indicating that the gene tagged in GT105628 is poorly expressed compared to the other genes identified in the screen (Figure 1f).

\section{Developmental expression of the GUS reporter gene}

We assessed the cell and tissue specificity of GUS expression from 1- and 3-day-old seedlings, 15-day-old plants, and leaves and inflorescences from mature plants. A summary of the GUS expression patterns in seedlings, developing leaves 
Table 1 Summary of GUS expression in various tissues of the five gene trap lines

\begin{tabular}{|c|c|c|c|c|c|}
\hline \multirow[b]{2}{*}{ Tissue } & \multicolumn{5}{|c|}{ GUS activity } \\
\hline & GT1345 & GT116224 & GT100789 & GT106424 & GT105628 \\
\hline \multicolumn{6}{|l|}{ Seedlings $^{a}$} \\
\hline Root & VT $(++)$ & ND & ND & ND & ND \\
\hline Hypocotyl & Ep $(+++)$ & $\mathrm{GC}(+++)$ & $\mathrm{GC}(++)$ & $\mathrm{GC}(++)$ & $\mathrm{GC}(+)$ \\
\hline Cotyledons & Ep $(+++)$ & $\mathrm{GC}(+++)$ & $\mathrm{GC}(+++)$ & $\mathrm{GC}(++)$ & $\mathrm{GC}(+)$ \\
\hline \multicolumn{6}{|l|}{ Rosette leaves } \\
\hline Primordia & $\mathrm{GC}(+++)$ & $\mathrm{GC}(+++)$ & $\mathrm{GC}(+++)$ & $\mathrm{GC}(++)$ & $\mathrm{GC}(+)$ \\
\hline $\begin{array}{l}\text { Immature } \\
\text { leaf }\end{array}$ & GC (+++) & $\mathrm{GC}(+++)$ & GC (++) & GC (++) & GC (+) \\
\hline $\begin{array}{l}\text { Mature } \\
\text { leaf }\end{array}$ & $\mathrm{GC}(+)$ & $\mathrm{GC}(+++)$ & $\mathrm{GC}(+)$ & $\mathrm{GC}(++)$ & $\mathrm{GC}(+)$ \\
\hline \multicolumn{6}{|l|}{ Flowers $^{\mathrm{b}}$} \\
\hline Sepals & $\mathrm{GC}(++)$ & $\mathrm{GC}(++)$ & $\mathrm{GC}(++)$ & $\mathrm{GC}(++)$ & $\mathrm{GC}(+)$ \\
\hline Petals & ND & ND & ND & ND & ND \\
\hline Stamens & $\mathrm{GC}(++)$ & $\mathrm{GC}(++)$ & $\mathrm{GC}(++)$ & $\mathrm{GC}(++)$ & $\begin{array}{l}\mathrm{Mi}, \\
\mathrm{GC}(+)\end{array}$ \\
\hline Carpels & $\begin{array}{l}\text { Ov, St, } \\
\text { GC (+++) }\end{array}$ & $\mathrm{GC}(++)$ & $\mathrm{GC}(++)$ & $\mathrm{GC}(++)$ & $\mathrm{GC}(+)$ \\
\hline Siliques $^{c}$ & $\begin{array}{l}\text { DS, AZ, } \\
\text { GC }(+++)\end{array}$ & $\mathrm{GC}(+)$ & $\mathrm{GC}(+)$ & $\mathrm{GC}(+)$ & $\mathrm{GC}(+)$ \\
\hline
\end{tabular}

a3-day-old seedlings.

b $\mathrm{Stage} 11$ flowers.

${ }^{c} 5$-days postfertilization siliques.

$A Z$, abscission zone; DS, developing seeds; Ep, epidermis; GC, guard cells; Mi, microspores; ND, not detected; Ov, ovules; St, stigmas; VT, vascular tissue. +++, strong GUS expression; ++, moderate GUS expression; +, weak GUS expression.

and reproductive organs is provided in Table 1, as a guideline for the expression profiles exhibited by the five gene trap lines.

The cell lineage that produces guard cells is initiated in the post-embryonic epidermis of the expanding cotyledons, immediately after the start of germination (Bergmann and Sack, 2007). One day after germination, GT1345 seedlings displayed a basipetal gradient of GUS activity in the epidermis of cotyledons, an acropetal gradient of GUS expression in hypocotyls, and localized signals in root tips (Figure 2a). At this stage, we did not observe staining of stomata on cotyledons (Figure 2a). As early as $20 \mathrm{~h}$ after the initiation of germination, GT116224 and GT100789 seedlings exhibited specific GUS activity in guard cells distributed on the expanding cotyledons (Figure 2f,k). One-day-old GT106424 and GT105628 seedlings did not display GUS staining in any tissue, indicating that neither gene is expressed during early events in seedling development (Figure 2p,u).

Three-day-old GT1345 seedlings displayed strong expression of the reporter in hypocotyls, cotyledons and in the upper part of the root vascular system, but exhibited preferential GUS expression in guard cells of both cotyledons and hypocotyls (Figure 2b,c). At the same developmental stage, seedlings of the other four lines displayed
GUS activity exclusively in stomata (Figure $2 \mathrm{~g}, \mathrm{~h}, \mathrm{l}, \mathrm{m}, \mathrm{q}, \mathrm{r}$, v,w). Dark-grown GT1345, GT116224 and GT100789 seedlings showed the same expression profiles as light-grown seedlings (Figure 2d,i,n). Conversely, we did not observe GUS activity in GT106424 and GT105628 dark-grown seedlings, suggesting that expression of the two tagged genes is dependent on light (Figure 2s,x).

Fifteen-day-old GT1345 plants displayed intense staining of lateral roots, hypocotyls, cotyledons, lodicules and true leaves (Figure 2e). Notably, GUS expression in the emerging leaves was restricted to guard cells on both the adaxial and abaxial epidermis. Lines GT116224, GT100789, GT106424 and GT105628 showed GUS expression exclusively in guard cells, distributed on cotyledons, hypocotyls and developing leaves (Figure 2j,o,t,y). GUS staining in GT100789 was more intense in young leaves compared to fully expanded cotyledons, thus confirming upregulation of the tagged gene during early stomatal development (Figure 20).

Like other cell types, stomata differentiate first at the leaf apex and later in the basal region (Telfer and Poethig, 1994). Staining of leaf primordia revealed a basipetal gradient of GUS activity that overlapped the normal pattern of maturation of stomata in all five lines (Figure $3 a, b, e, f, i, j, m, n, q, r)$. In immature GT1345 rosette leaves, we detected very intense guard cell-specific signals (Figure 3c), whereas GUS activity decreased in fully expanded leaves, indicating a negative correlation between gene expression and leaf development (Figure 3d). Similarly, GT100789 plants displayed a progressive reduction of GUS expression during maturation of the leaf (Figure 3k,I). In GT116224, GT106424 and GT105628 lines, we did not detect any substantial change in the intensity of GUS staining between stomata distributed on young versus mature rosette leaves (Figure $3 g, h, 0, p, s, t$ ).

Finally, we investigated expression of the reporter gene in stems, flowers and siliques from adult plants. All five EXOTIC lines showed specific signals in stomata distributed on the stems of both primary and secondary inflorescences (data not shown). Prior to pollination, GT1345 flowers revealed guard cell-specific GUS expression in sepals, anthers, carpels and styles, in addition to intense staining of stigmatic tissues and ovules (Figure 4a). Three days after pollination, we detected the same expression profile as in unfertilized flowers (Figure 4b). In young GT1345 siliques, we observed high levels of GUS expression in stomata distributed on carpels, but also in developing seeds, abscission zones and styles (Figure 4c,d). In GT116224, GT100789 and GT106424 lines, GUS signals were restricted to guard cells localized on sepals, anthers and carpels, in both unfertilized and fertilized flowers (Figure 4e-g). In flowers of the GT105628 line, we detected weak expression of the reporter in stomata, and occasionally in developing anthers (Figure $4 \mathrm{~h}-\mathrm{k}$ ). Starting with the formation of microspores, faint GUS signals became visible in young pollen sacs (Figure 4i). As flower development progressed, we observed 
Figure 2. GUS expression patterns in seedlings and young plants.

(a-e) GT1345, (f-j) GT116224, (k-o) GT100789, (pt) GT106424, (u-y) GT105628. GUS assays were performed on 1-day-old seedlings $(a, f, k, p, u)$, 3-day-old seedlings (b, g, l, q, v), dark-grown seedlings ( $d, i, n, s, x)$ and 15 -day-old plants $(e, j$, $o, t, y)$. Tissues were incubated in the staining solution for $6 \mathrm{~h}(\mathrm{a}-\mathrm{e}), 24 \mathrm{~h}(\mathrm{f}-\mathrm{t})$ or $60 \mathrm{~h}(\mathrm{u}-\mathrm{y})$. The boxed images in (i) and ( $\mathrm{n}$ ) are magnified views $(90 \times)$ of cotyledons. Scale bars represent $1 \mathrm{~mm}$.
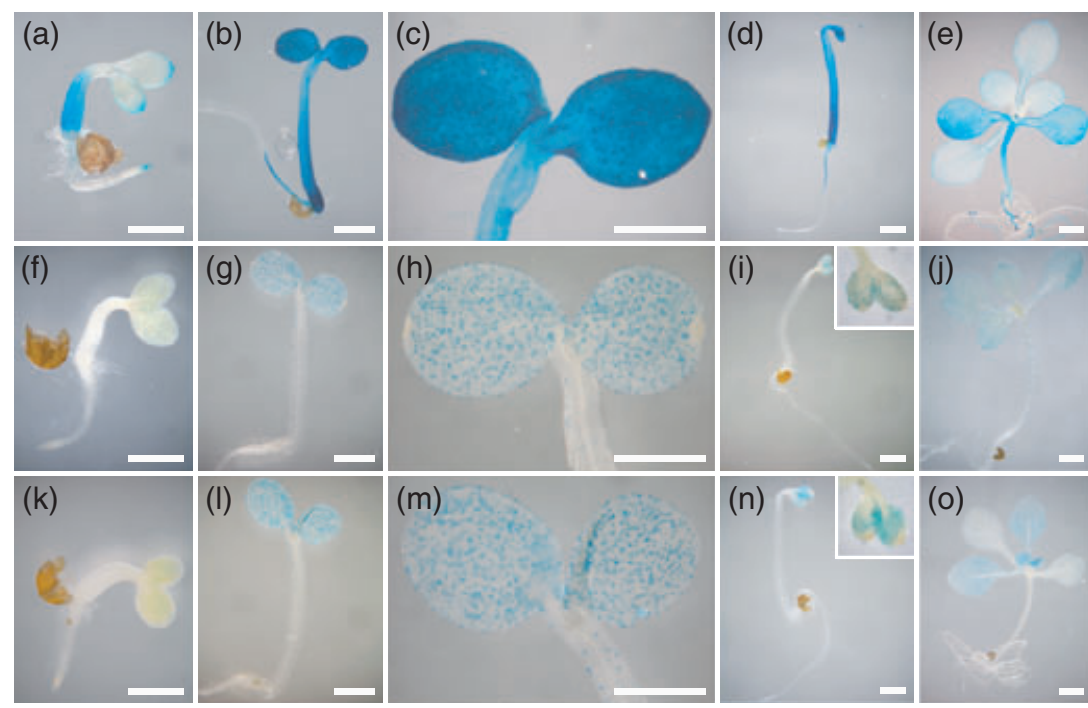

(0)
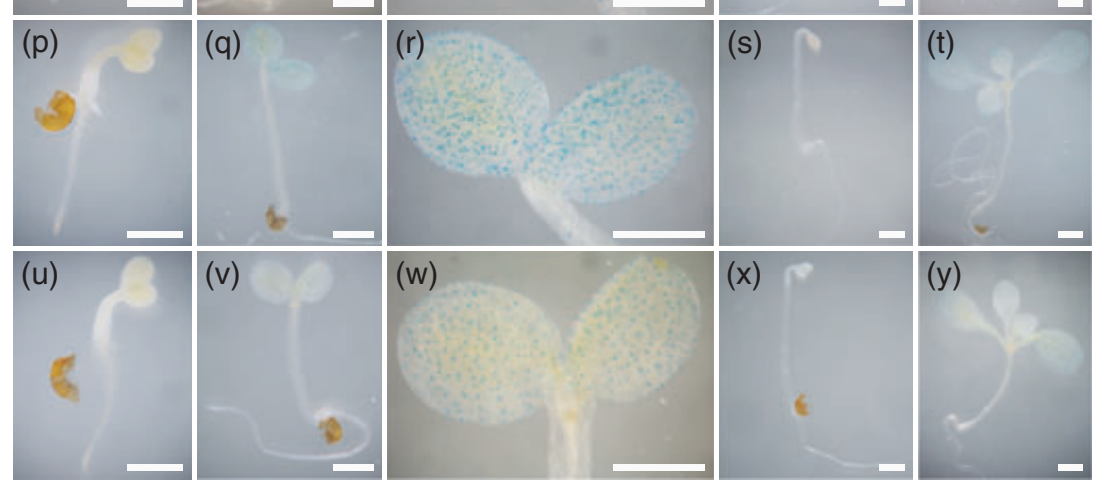

staining of immature microspores (Figure 4j). However, we did not detect GUS activity in mature pollen grains at anthesis (Figure 4k).

\section{Identification of chromosomal DsG insertion sites}

We performed thermal asymmetric interlaced PCR (TAILPCR) experiments to amplify the genomic regions flanking the DsG insertion in the selected lines (Liu et al., 1995). Specific TAIL-PCR products were directly sequenced and aligned to the Arabidopsis genome using the BLAST program (http://www.ncbi.nlm.nih.gov/BLAST/). Chromosomal insertion sites were confirmed by PCR amplification of junction fragments, using a gene-specific primer in combination with a $D s G$ primer.

In GT1345, we identified a DsG element inserted 6 bp after the translational start codon of the At $4 \mathrm{~g} 00360$ gene encoding CYP86A2 mono-oxygenase (Figure 5a). In GT105628, we found a gene trap insertion in the 4th intron of the AtPDR3 gene (At2g29940), belonging to the large $A B C$ transporter gene family (Figure 5a). RT-PCR amplification of cDNAs derived from homozygous GT1345 and GT105628 plants revealed the absence of the wild-type transcript, and the presence of a transcriptional fusion between the trapped gene and the GUS gene (Figure S1). Sequencing of PCR products indicated that the reporter had been fused in-frame with upstream sequences equivalent to six nucleotides of the CYP86A2 gene in GT1345, and 651 nucleotides of the AtPDR3 gene in GT105628 (Figure S1). The corresponding gene products are predicted to lack all the CYP86A2 and AtPDR3 functional domains, and are thus expected to be non-functional proteins.

In the GT116224, GT100789 and GT106424 lines, we mapped the $D s G$ element outside annotated genes in three intergenic regions on chromosome 1, 2 and 5, respectively (Figure 5a). These insertions are therefore not expected to impair any gene function.

\section{Gene expression analyses in purified guard cells}

We performed RT-PCR experiments on cDNAs derived from pure preparations of guard cells and mesophyll cells to further investigate the expression profile of the endogenous CYP86A2 and AtPDR3 genes. Cells were harvested from wild-type immature rosette leaves, using the laser capture microdissection (LCM) technique (Kerk et al., 2003). The quality and specificity of cDNAs from LCM-harvested cells were evaluated by testing expression of the constitutive 

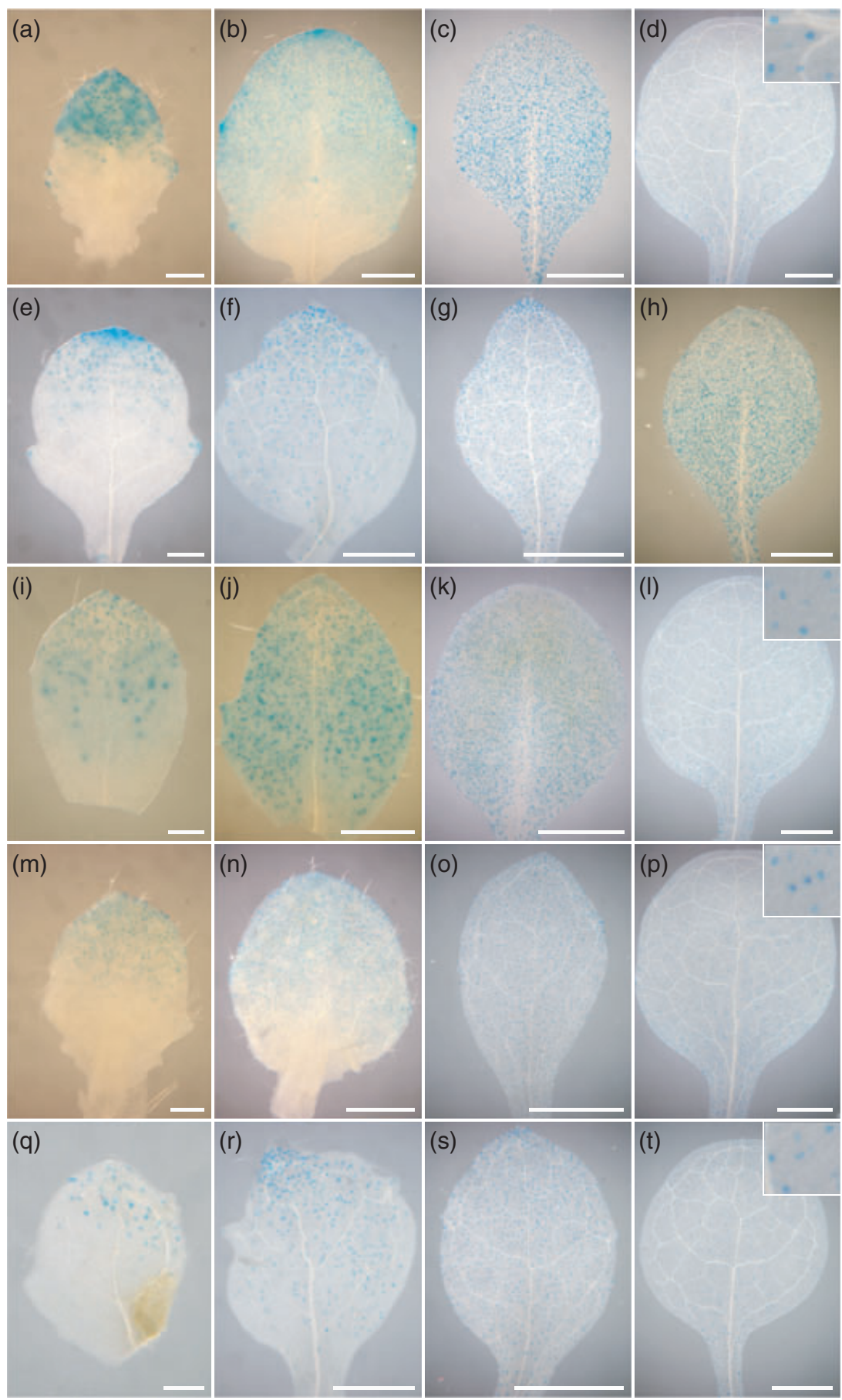
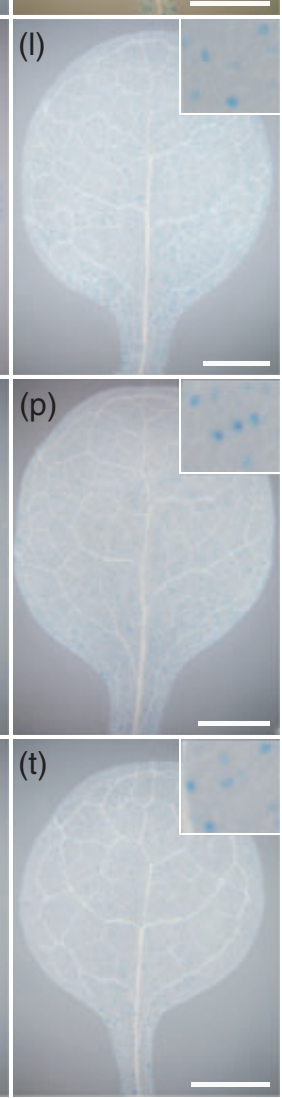

Figure 3. GUS expression patterns in rosette leaves.

(a-d) GT1345, (e-h) GT116224, (i-I) GT100789, (m-p) GT106424, (q-t) GT105628. GUS assays were performed on leaf primordia $(a, b, e, f, i, j$, $\mathrm{m}, \mathrm{n}, \mathrm{q}, \mathrm{r})$, expanding leaves $(\mathrm{c}, \mathrm{g}, \mathrm{k}, \mathrm{o}, \mathrm{s})$ and mature leaves $(d, h, I, p, t)$. Tissues were incubated in staining solution for $6 \mathrm{~h}(\mathrm{a}, \mathrm{b})$, $24 \mathrm{~h}(\mathrm{c}-\mathrm{p})$ or $60 \mathrm{~h}(\mathrm{q}-\mathrm{t})$. Scale bars represent $0.2 \mathrm{~mm}(a, e, i, m, q), 0.5 \mathrm{~mm}(b, f, j, n, r)$ or $1 \mathrm{~mm}$ (c, d, g,h,k,l,o,p,s,t).
ACTIN2 gene and the guard cell-specific AtMYB60 gene (Cominelli et al., 2005). As shown in Figure 5(b), we amplified transcripts for both CYP86A2 and AtPDR3 exclusively from purified guard cells.

Consistent with the relative intensity of GUS staining observed in stomata of GT1345 and GT105628 leaves, we detected higher levels of expression for CYP86A2, compared to AtPDR3.
Next, we employed RT-PCR analyses of LCM-derived cells to gain more insight into the guard cell-specific GUS expression patterns generated by the gene trap insertions that occurred in intergenic regions (i.e. lines GT116224, GT100789 and GT106424). It is important to note that the $3^{\prime}$ ends of the $A c / D s$ transposable elements contain minimal promoters that can be activated by neighbouring cis-acting elements (Cocherel et al., 1996). Consequently, transposon- 
Figure 4. GUS expression patterns in flowers and siliques.

(a-d) GUS activity in unfertilized (a) and fertilized (b) flowers, and developing siliques (c, d) of line GT1345.

(e-g) Guard cell-specific GUS expression in fertilized flowers from lines GT116224 (e), GT100789 (f) and GT106424 (g).

(h-k) GUS activity in GT105628 inflorescences (h) and flower buds at stages $10(\mathrm{i}), 11(\mathrm{j})$ and $12(\mathrm{k})$. The arrowheads in (h) indicate GUS expression in anthers of stage 10 buds (black arrowheads) and stage 11 buds (white arrowhead). In (i) and (j), petals and sepals were manually removed. Scale bars represent $1 \mathrm{~mm}$.
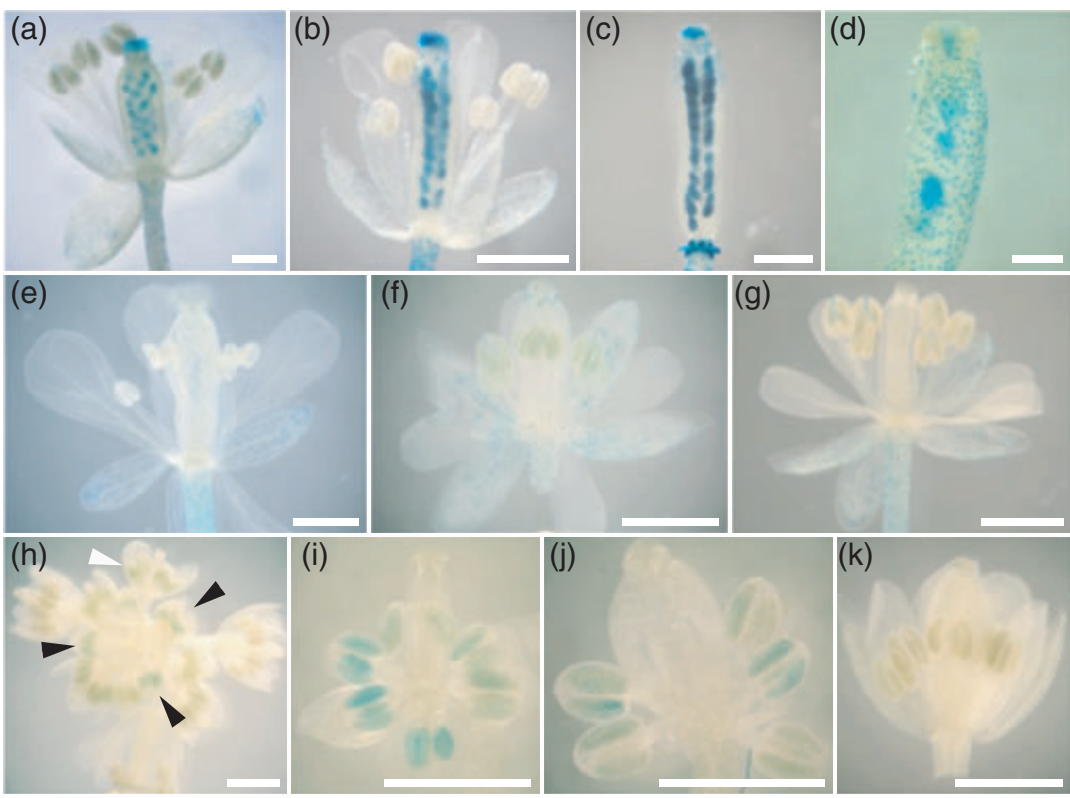

(a)

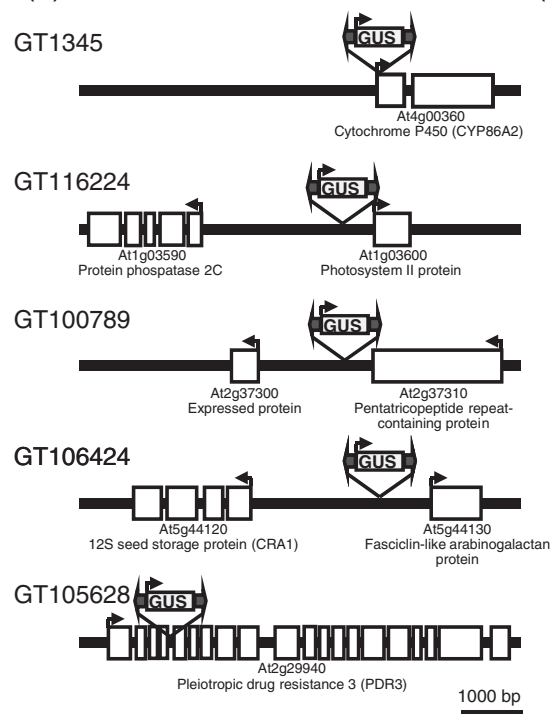

(b)

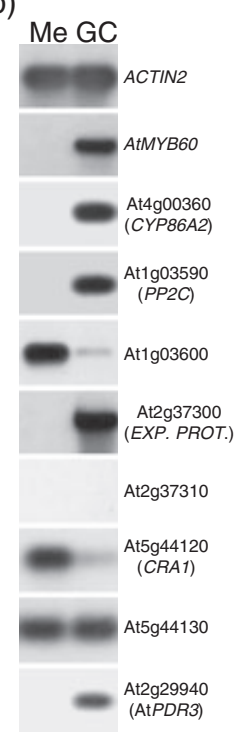

Figure 5. Identification of chromosomal insertion sites and analysis of gene expression in LCM-purified guard cells.

(a) Genomic regions flanking the gene trap insert in the five gene trap lines. Gene structures and descriptions are based on those at http://www. arabidopsis.org/. White boxes represent exons. The position of the ATG start codon and the direction of transcription are indicated (black arrows). In the $D s G$ trapping element, only the transposon terminal inverted repeats (arrows) and the GUS coding region are represented (not to scale).

(b) RT-PCR analysis of gene expression in mesophyll cells (Me) and guard cells (GC) purified from wild-type immature rosette leaves. Target sequences and control genes (ACTIN2 and AtMYB60) were amplified for 25 cycles, with the exception of At2g37310 and At2g29940 (AtPDR3), which were amplified for 40 cycles.

based gene-trapping systems can also function as enhancer traps (Nakayama et al., 2005). One possible explanation for GUS expression in the stomata of GT116224, GT100789 and

GT106424 is the presence of guard cell-specific cis-elements in the vicinity of the insertion sites. If this assumption is correct, one or more genes adjacent to the $D s G$ element would be preferentially expressed in stomata. We analyzed the expression of genes flanking the gene trap element in the three lines to verify this hypothesis (Figure $5 \mathrm{~b}$ ). Interestingly, the PROTEIN PHOSPHATASE 2 C gene (At1g03590), located downstream of the trapping element in GT116224, was only expressed in guard cells. In contrast, expression of the At1g03600 PHOTOSYSTEM II PROTEIN gene, situated upstream of the insertion site in GT116224, was downregulated in guard cells compared to mesophyll cells. Of the two genes surrounding the DsG insertion in GT100789, the At2g37300 expressed protein gene was selectively expressed in guard cells, but we did not detect expression of the At2g37310 PENTATRICOPEPTIDE REPEAT-CONTAINING PROTEIN gene, either in stomata or mesophyll cells (Figure 5b). Finally, neither gene flanking the trapping element in GT106424 was preferentially expressed in stomata. In fact, expression of the 12S SEED STORAGE CRA1 gene (At5g44120) was drastically reduced in guard cells, and the transcript abundance for the FASCICLIN-LIKE gene (At5g44130) did not vary between purified stomata and mesophyll cells (Figure 5b).

\section{Bioinformatic identification of putative cis-regulatory elements}

Genes with similar expression profiles often share common cis-regulatory elements in their promoters. Data from GUS profiling and expression analyses in LCM-derived guard cells suggest that the gene trap insertions described in this 
study might identify cis-acting elements that drive expression in stomata. We used the motif-finding program AlignACE 3.0 (http://atlas.med.harvard.edu, Hughes et al., 2000) to identify common sequence motifs in the regions flanking the insertion sites. In the analysis, we included $1000 \mathrm{bp}$ of the genomic sequences upstream of the translational start sites of CYP86A2 and AtPDR3, and the full-length intergenic regions surrounding the $D s G$ element in GT116224, GT100789 and GT106424. AlignACE found a strong signal for an AG-reach sequence, which contained the AAAG core motif, that is required for binding of DOF-type transcription factors (Yanagisawa and Schmidt, 1999). To evaluate the significance of the occurrence of AAAG oligonucleotides in the regions included in the analysis, a $P$-value was calculated for the expected frequency of AAAG motifs in the complete set of Arabidopsis intergenic sequences. With the exception of the putative AtPDR3 promoter, all the chromosomal regions flanking the $D s G$ insertions were significantly enriched in AAAG target sites $(P \leq 0.01)$. This finding is of particular interest because clusters of [A/T]AAAG oligonucleotides have been demonstrated to be essential for guard cell-specific expression of the potato potassium channel KST1 gene (Plesch et al., 2001). In Arabidopsis, [A/T]AAAG clusters have been identified in the promoter of various genes that are expressed in stomata, including the potassium channel $K A T 1$, the orthologue of the potato $K S T 1$ gene (Nakamura et al., 1995; Plesch et al., 2001).

Based on results from studies on the KST1 and KAT1 promoters, we analysed the regions flanking the trapping elements more thoroughly, to determine the presence of putative guard cell-specific cis-regulatory elements, defined as clusters of at least three [A/T]AAAG motifs located on the same strand within a region of at most $100 \mathrm{bp}$. We searched the genomic regions previously analyzed with the AlignACE program for sequences where the motif count could be considered as statistically significant $(P \leq 0.01$, see Experimental procedures). As summarized in Table 2, the promoter region of the KAT1 gene contains three such guard cell-specific clusters, located in proximity to the ATG codon. In the presumed promoter of CYP86A2, we found two adjacent sequences enriched in [A/T]AAAG clusters, but we did not identify putative guard cell-specific cis-elements upstream of the AtPDR3 gene (Table 2). In the intergenic region between At1g03590 and At1903600, flanking the gene trap insert in GT116224, we discovered four [A/ T]AAAG clusters (Figure 5a and Table 2). Interestingly, three of these clusters occurred in a $903 \mathrm{bp}$ region proximal to the translation start codon of At1g03590, whose expression was upregulated in LCM-harvested guard cells (Figure $5 b)$. In the chromosomal region between At2g37300 and At2g37310, targeted by the trapping element in GT100789, we found two clusters of DOF-binding motifs (Figure 5a and Table 2). One cluster was located in close proximity to the ATG codon of the guard cell-specific At2g37300 gene (Figure $5 \mathrm{~b}$ ), while the second cluster was next to the DsG insertion site (Figure 5a and Table 2). Finally, we identified three [A/T]AAAG clusters in the intergenic region tagged in GT106424 (Figure 5a and Table 2). The first [A/T]AAAG cluster was mapped at $558 \mathrm{bp}$ from the translational start codon of At5g44120, the second one occurred at $443 \mathrm{bp}$ upstream of the trapping element, whereas the third cluster was located at $+339 \mathrm{bp}$ from the insertion site, presumably in the promoter region of At5g44130 (Table 2).

Table 2 Occurrence of [A/T]AAAG clusters in the chromosomal regions flanking the $D s G$ insertion sites

\begin{tabular}{|c|c|c|c|c|c|}
\hline Line & Gene & Description & $\begin{array}{l}\text { Distance from } \\
\text { ATG (bp) }\end{array}$ & $\begin{array}{l}\text { Distance from } \\
D s G(\mathrm{bp})\end{array}$ & $P$-value \\
\hline & At5g46240 & Potassium channel protein (KAT1) & -4 & & 0.0013 \\
\hline & & & -50 & & 0.0001 \\
\hline & & & -524 & & 0.01 \\
\hline \multirow[t]{2}{*}{ GT1345 } & At4g00360 & Cytochrome P450 (CYP86A2) & -805 & -811 & 0.0021 \\
\hline & & & -883 & -889 & 0.0007 \\
\hline \multirow[t]{4}{*}{ GT116224 } & At1g03590 & Protein phosphatase $2 \mathrm{C}$ & -165 & -1959 & 0.0070 \\
\hline & & & -361 & -1753 & 0.0003 \\
\hline & & & -903 & -1154 & 0.0007 \\
\hline & & & -1384 & -662 & 0.001 \\
\hline \multirow[t]{2}{*}{ GT100789 } & At2g37300 & Expressed protein & -40 & -1214 & 0.0009 \\
\hline & & & -1209 & -89 & 0.01 \\
\hline \multirow[t]{3}{*}{ GT106424 } & At5g44120 & 12S seed storage protein (CRA1) & -558 & -1364 & 0.0022 \\
\hline & & & -1479 & -443 & 0.0001 \\
\hline & & & -2261 & +339 & 0.0068 \\
\hline \multirow[t]{3}{*}{ GT106424 } & At5g44130 & Fasciclin-like protein & -538 & +339 & 0.0068 \\
\hline & & & -1382 & -443 & 0.0001 \\
\hline & & & -2269 & -1364 & 0.0022 \\
\hline GT105628 & At2g29940 & Pleiotropic drug resistance 3 (AtPDR3) & $-{ }^{a}$ & $-{ }^{a}$ & $--^{a}$ \\
\hline
\end{tabular}

${ }^{a}$ No [A/T]AAAG clusters were identified in a 1000-bp region upstream of the ATG codon of At2g29940. 


\section{Phenotypic analyses of the gene trap lines}

Gene trap insertions identify patterns of gene expression but also generate mutations by disrupting gene functions. In addition to assessing reporter expression profiles, we scored the five gene trap lines for visible mutant phenotypes. Under standard growth conditions, plants homozygous for $D s G$ insertions did not show any macroscopic morphological or developmental abnormalities. Examination of leaf anatomy did not reveal significant differences in stomatal density and stomatal index [100 $\times$ stomatal density/(stomatal density + epidermal cell density)] between the trapping lines and the wild-type (Figure 6a,b). Similarly, we did not detect defects in shape, size or patterning of stomata in any of the lines analysed in this study.

A mutant allele of CYP86A2 (cyp86a2-1, also known as att1, for aberrant induction of type three genes 1) has been previously described (Xiao et al., 2004). att1 plants showed increased sensitivity to dehydration and a higher transpiration rate compared to the wild-type. Interestingly, the enhanced water loss did not result from defects in stomatal opening and closing, but was due to alterations in the composition and structure of the cuticle membrane, which showed increased permeability to water vapour (Xiao et al., 2004). We performed a toluidine-blue (TB) test to highlight defects in the cuticle of GT1345 plants. Leaves with a normal cuticle are impermeable to TB staining, but a deficient cuticle allows the TB dye to permeate the epidermal surface (Tanaka et al., 2004). Wild-type plants were insensitive to TB (Figure 6c, left panel), but homozygous GT1345 plants showed staining over the whole surface, indicating extensive loss of the cuticle layer (Figure 6c, right panel).
The AtPDR3 gene, which is trapped in GT105628, encodes an $A B C$-type transporter protein. These transporters derive energy from the hydrolysis of ATP to move molecules and ions through membranes. Interestingly, two full-size $A B C$ transporters, AtMRP4 and AtMRP5, have been shown to be preferentially expressed in guard cells, and to function in the modulation of stomatal activity (Klein et al., 2003, 2004). We performed stomatal aperture assays to test whether the loss of the AtPDR3 gene function affected guard-cell responses. Stomata from wild-type and homozygous GT105628 plants showed similar behaviour under both dark and light conditions (Figure 6d). Conversely, ABA-induced stomatal closing was significantly reduced in GT105628 leaves, compared to the wild-type, indicating that loss of the AtPDR3 gene function altered the sensitivity of guard cells to the hormone.

\section{Discussion}

\section{Identification of gene trap lines with a guard cell-specific GUS expression pattern}

We have described a genetic screen that used Arabidopsis gene traps to identify novel genes expressed in stomata. By analysing GUS expression patterns in nearly 20000 EXOTIC lines, we identified five lines showing preferential or exclusive expression of the reporter in guard cells. Given that approximately $70 \%$ of $D s G$ insertions occur in transcribed regions (Parinov et al., 1999), and that $50 \%$ of the time the GUS gene is found in the same orientation as the tagged gene, we estimate that expression profiles of approximately 7000 genes were examined in this work. The total number of guard cell-positive lines identified in the screen appears
Figure 6. Phenotypic analyses of the gene trap lines.

Comparison of (a) stomatal density and (b) stomatal index in leaves from wild-type and homozygous gene trap lines (means \pm standard errors).

(c) TB staining in wild-type (left panel) and GT1345/cyp86a2 homozygous plants (right panel). Intense staining of the GT1345/cyp86a2 mutant indicates disruption of the normal cuticle layer. Scale bars represent $1 \mathrm{~mm}$.

(d) Stomatal aperture measurements in wildtype and GT105628/atpdr3 epidermal strips determined after $3 \mathrm{~h}$ of exposure to dark, light or $5 \mu \mathrm{M}$ ABA. Data represent the means of three separate experiments $(n=240$ stomata per experiment), \pm standard errors. The asterisk indicates a statistically significant difference in ABAinduced stomatal closure between wild-type and GT105628/atpdr3 leaves ( $t$-test; $P<0.05)$.

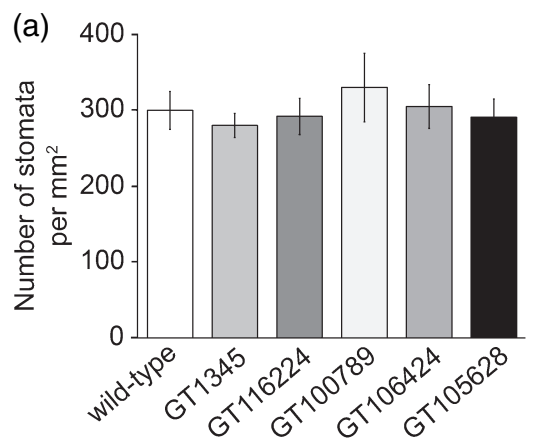

(c)

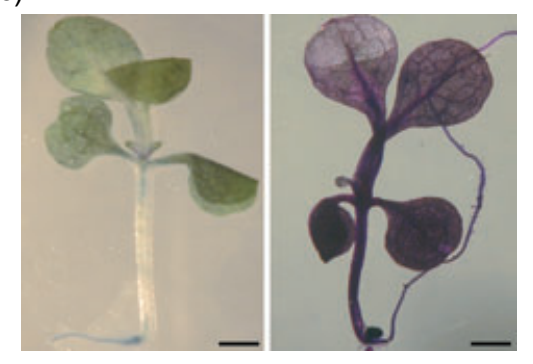

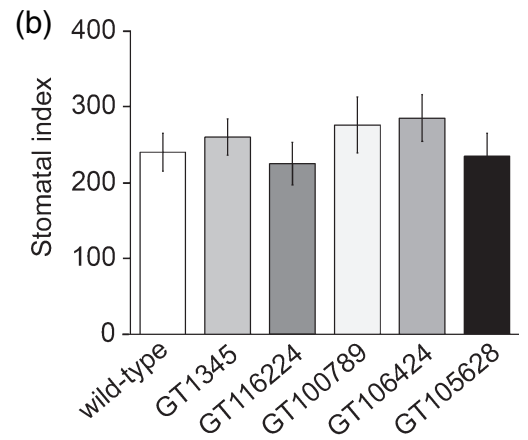

(d)

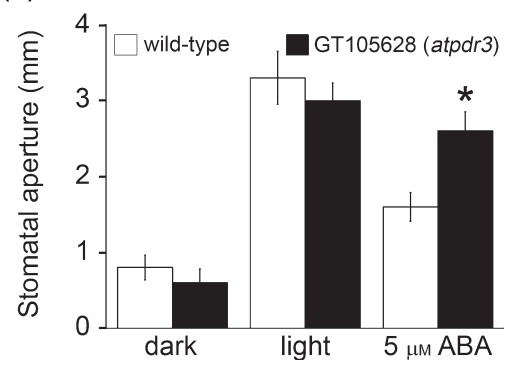


extremely low when compared to results from other studies. A microarray-based survey of gene expression in leaf tissues identified 64 putative guard cell-specific genes, corresponding to $0.7 \%$ of the Arabidopsis genome (Leonhardt et al., 2004). Large-scale gene trap screens probably underestimate the number of cell-specific genes compared with microarray analyses, as they examine gene expression qualitatively rather than quantitatively. The analysis of GUS expression patterns is visual, and has a threshold of detection that differs from the sensitivity of microarray-based experiments. Nevertheless, it is important to note that data from our study and from microarray analyses both indicate that the highly specialized developmental and response stomatal pathways require relatively few specific genes, and mostly rely on shared gene functions that are active in various cell types.

\section{Genes tagged in the screen}

In GT1345, the DsG element disrupted the cytochrome P450 CYP86A2 gene (Figure 5a and Figure S1). The Arabidopsis genome contains 246 cytochrome $\mathrm{P} 450$ genes, divided into various sub-families based on sequence similarity and function (Paquette et al., 2000). The five members of the CYP86A subfamily catalyze the metabolism of fatty acids and alkanes through $\omega$-hydroxylation (Wellesen et al., 2001). A mutant allele of CYP86A2, named att1, has been previously identified in a screen for upregulation of effector bacterial genes in leaves infected with Pseudomonas syringae (Xiao et al., 2004). The att 1 mutant contains only $30 \%$ of the cutin monomers found in wild-type, and has a loose cuticle membrane ultrastructure (Xiao et al., 2004). Likewise, homozygous GT1345 plants lacked a normal cuticle structure, as revealed by complete permeability to TB staining, confirming the essential role of CYP86A2 in cuticle membrane development (Figure 6c).

Both guard cells and substomatal cavities are covered with a continuous cuticle in Arabidopsis leaves. GUS expression analyses in GT1345 indicated that CYP86A2 is expressed in the epidermis of young tissues, with preferential localization in guard cells (Figures 1a, 2a-e and 3a-d). The GUS expression patterns are compatible with a role for CYP86A2 in cutin monomer biosynthesis, and emphasize its involvement in cuticle deposition in stomata. In addition to defects in the cuticle layer, the att1 mutation results in the upregulation of bacterial virulence genes and enhanced disease symptoms after inoculation with $P$. syringae (Xiao et al., 2004). Stomatal pores are a primary site of bacterial entry, and function as innate immunity gates that actively prevent infections (Melotto et al., 2006). Interestingly, overexpression of GFP-tagged type III bacterial genes in the att1 mutant specifically occurs in substomatal chambers (Xiao et al., 2004). The expression of CYP86A2 in guard cells, as revealed by the GUS expression pattern in GT1345 and RT-
PCR analysis of LCM-purified stomata, provides further support for involvement of the CYP86A2 protein in stomatal responses to pathogen attacks. Cutin monomers synthesized by CYP86A2 in stomata could contribute to the repression of bacterial gene expression, either by blocking the activity of positive host factors, or by directly suppressing virulence gene expression.

In flowers and siliques from GT1345 plants, we observed GUS expression in developing seeds and stigmatic tissues, in addition to stomata (Figure $4 a-d$ ). Interestingly, expression of the gene in the stigma was confirmed by microarraybased expression profiling of Arabidopsis pistils, in which CYP86A2 was described as specifically expressed in papillar cells (Tung et al., 2005). These findings suggest that CYP86A2 is probably involved in biogenesis of the cuticle in both vegetative and reproductive tissues.

In GT105628, we found a $D s G$ insertion in the $A B C$ transporter gene AtPDR3 (Figure 5a and Figure S1). More than $130 \mathrm{ABC}$ transporters, organized in 14 sub-families, have been found in the Arabidopsis genome (SanchezFernandez et al., 2001). Although other ABC transporters have been intensively studied in plants, the PDR sub-family has not been well characterized. GUS expression analyses in GT105628 indicated that the AtPDR3::GUS fusion is weakly but specifically expressed in stomatal guard cells and developing pollen grains (Figures $1 e, f, 2 u-y$ and $3 q-t$, $4 \mathrm{~h}-\mathrm{k}$ ). The GUS expression patterns are compatible with the results from a comprehensive RT-PCR analysis of Arabidopsis PDR genes, which showed that AtPDR3 is only expressed in leaves and young flowers (Van de Brule and Smart, 2002). A detailed transcriptome analysis of the male gametophyte indicated that AtPDR3 is expressed in uninucleate microspores and bicellular pollen, and that its expression declines in immature tricellular pollen and mature pollen grains (Honys and Twell, 2004). This developmental profile of AtPDR3 expression in microspores precisely mirrors GUS expression in GT105628 anthers (Figure 4h-k). Despite the expression of AtPDR3 in developing pollen grains, we did not detect defects in pollen development and viability, as revealed by segregation of the kanamycin resistance trait in the progeny of reciprocal crosses between homozygous GT105628 and wild-type plants (data not shown).

AtPDR3 expression in guard cells could suggest a role for the transporter in guard-cell differentiation or stomatal activity. Homozygous GT105628 plants did not show abnormalities in the development and distribution of guard cells (Figure $6 a, b$ ). Analyses of stomatal movement in response to dark, light and $A B A$ indicated that loss of the AtPDR3 gene function significantly altered the response of guard cells to ABA (Figure $6 \mathrm{~d}$ ). In guard cells, ABA triggers a signalling cascade that induces rapid closure of the stomatal pore. Stomata from GT105628 leaves showed a hyposensitive response to the hormone, indicating a role for AtPDR3 as a 
positive regulator of $A B A$ signalling in guard cells. Two other $A B C$ transporters, AtMRP4 and AtMRP5, which belong to the multi-drug resistance-associated protein subfamily (MRP), have been demonstrated to regulate stomatal activity (Klein et al., 2003, 2004). Interestingly, mutations in AtMRP5 severely reduce the sensitivity of guard cells to $A B A$, resulting in nearly complete suppression of $A B A$-induced stomatal closure (Klein et al., 2003). The phenotype exhibited by homozygous GT105628 plants functionally links the cell-specific expression of AtPDR3 to guard-cell activity, and indicates the involvement of PDR-type $A B C$ transporters in the regulation of stomatal signalling pathways, in addition to that of MRP proteins.

\section{Gene trap insertions outside transcription units}

In GT116224, GT100789 and GT106424, DsG insertions occurred outside annotated genes (Figure $5 \mathrm{a}$ ). This result is to some extent unexpected, as gene trap systems are designed to be activated only following integration in transcription units. Nevertheless, extensive screens of trapping lines indicated that insertions in non-coding regions very often result in distinct GUS expression profiles (Nakayama et al., 2005). Two hypotheses can be formulated to explain the guard cell-specific activation of the reporter in GT116224, GT100789 and GT106424. First, the DsG element could be tagging as yet unannotated genes that are preferentially expressed in stomata. However, re-examination of the chromosomal regions neighbouring the insertion sites, using the Arabidopsis Tiling Array Transcriptome Express Tool (Yamada et al., 2003), did not reveal the presence of any significant expressed sequence. In agreement, RT-PCR experiments performed on cDNAs prepared from leaves of the three lines failed to amplify GUS fusion transcripts, either in the sense or antisense orientation (data not shown).

Alternatively, transcription of the reporter could initiate within the trapping element, and come under the control of guard cell-specific cis-elements located in the vicinity of the insertion site. This second hypothesis may account for the GUS expression patterns generated by the gene trap insertions in GT116224 and GT100789. Indeed, both the At1g03590 and At2g37300 genes, located upstream of the DsG element in GT116224 and GT100789, respectively, are specifically expressed in purified guard cells (Figure $5 a, b$ ). We reasoned that common regulatory DNA motifs, presumably located in the promoters of At $1 \mathrm{~g} 03590$ and At2g37300, mediate expression of both the reporter and the endogenous genes. GUS expression in GT100789 was developmentally regulated, with stomata distributed on juvenile leaves showing stronger reporter activity (Figures 20 and 3i-I). Data from microarray hybridization experiments indicate that At $2 \mathrm{~g} 37300$ expression is upregulated in young rosette leaves compared to adult and senescent leaves (Zimmermann et al., 2004). This observation provides fur- ther support for involvement of the At2g37300 promoter in driving GUS expression in GT100789.

At1g03590 encodes a PROTEIN PHOSPHATASE 2C (PP2C) belonging to the plant-specific homology group 1v. At least 69 putative PP2C proteins have been identified in the Arabidopsis genome, of which only a few have been experimentally characterized (Kerk et al., 2002). Among them, ABA-INSENSITIVE1 and 2 (ABI1 and 2) and HYPERSENSITIVE TO ABA1 (HAB1) have been reported to mediate $A B A$ responses in several plant organs, including stomata (Gosti et al., 1999; Merlot et al., 2001; Saez et al., 2004). In guard cells, $A B \mid 1$ and $A B I 2$ regulate early signal transduction events, upstream of the ABA-induced increase in cytoplasmic calcium that precedes stomatal closure (Allen et al., 1999). Based on the expression of At1g03590 in guard cells, it is intriguing to speculate that the encoded PP2C-1v protein represents a new component of the protein phosphates regulatory network that mediates $A B A$ responses in stomata.

The At2g37300 gene, identified in GT100789, is a singlecopy gene, encoding a predicted $1.4 \mathrm{kDa}$ unknown protein that lacks any obvious functional domain. Notably, over $30 \%$ of the 64 putative guard cell-specific genes identified in a microarray analysis of gene expression in stomata encode proteins of unknown function (Leonhardt et al., 2004). Many of the genes involved in the modulation of stomatal activity were originally identified in genetic screens for mutations affecting $A B A$ responses in seeds or whole plants. We speculate that this rather indirect approach has failed to uncover several components of the stomatal signalling and developmental pathways. Uncharacterized genes that are preferentially expressed in guard cells, such as At2g37300, are potential candidates involved in stomatal signal transduction and development, and are of particular interest for future studies.

Finally, neither gene flanking the trapping element in GT106424 (i.e. At5g44120 and At5g44130) was preferentially expressed in stomata (Figure $5 a, b$ ). It is thus unlikely that cis-acting elements that control expression of the endogenous genes also support GUS activity in guard cells. We considered the possibility that, in GT106424, the trapping element could identify a cryptic promoter that retains the ability to control gene expression in guard cells. Cryptic promoters are normally silent, but can be re-activated upon insertion of promoter-less reporter genes in their vicinity (Sivanandan et al., 2005). Several tissuespecific cryptic promoters have been discovered in gene tagging screens in Arabidopsis (Sivanandan et al., 2005). Most significantly, Plesch et al. (2000) identified two cryptic promoters that are capable of driving the expression of reporter genes in stomata, suggesting that silent cisregulatory elements that are suitable for gene expression in guard cells might be relatively frequent in the Arabidopsis genome. 


\section{Analysis of putative guard cell-specific cis-acting elements}

Gene expression in guard cells probably relies on transcriptional mechanisms, employing cis-acting elements and their cognate transcription factors (Plesch et al., 2001). Studies indicate a role for DNA consensus sequences for DOF proteins as putative guard cell-specific cis-active enhancers (Plesch et al., 2000, 2001). Importantly, Plesch et al. (2001) demonstrated that target mutations of [A/T]AAAG clusters, located in the promoter of the guard cell-specific KST1 gene from potato, completely suppress gene expression in stomata.

We identified genomic regions significantly enriched in [A/T]AAAG motifs in most of the chromosomal sites flanking the DsG insertions described in this study (Table 2). The majority of $[A / T] A A A G$ clusters occurred in the putative promoters of genes that are highly expressed in stomata, including CYP86A2, the At1g03590 PP2C gene and the At2g37300 expressed protein gene (Table 2 and Figure 5b). Some of the identified cis-elements, such as the two adjacent clusters located upstream of CYP86A2, were found at a longer distance from the coding sequence compared with the distribution of the $[A / T] A A A G$ motifs in the promoter of the KAT1 reference gene. Such a distance could account for the lack of cell-specific expression of CYP86A2 in seedling tissues and floral organs (Figures 2a-e and $4 a-d$ ).

Interestingly, we identified two putative guard cell-specific cis-elements in the vicinity of the DsG insertion in GT106424, suggesting the presence of a cryptic stomataspecific promoter (Table 2). However, we failed to identify sequences enriched in DOF-binding sites in a 1000 bp region upstream of the guard cell-specific AtPDR3 gene, but found an $[\mathrm{A} / \mathrm{T}] \mathrm{AAAG}$ cluster in the putative promoter of the CRA1 gene, whose expression was downregulated in stomata (Table 2 and Figure 5b).

Taken together, these observations lend further support to the notion that DOF target sites contribute to mediation of gene expression in stomata. They also indicate that multiple [A/T]AAAG clusters may have additive effects on driving guard-cell specific expression, and that spacing within clusters, or between clusters and genes, probably influences their activity. Importantly, our findings indicate a nonexclusive role for DOF recognition DNA motifs in the regulation of transcription in stomata. The weak guard cellspecific expression of AtPDR3 could be mediated by as yet unknown cis-control elements, through the involvement of transcription factors other than DOF proteins. In this perspective, the specificity and intensity of expression in guard cells are most likely controlled by a network of regulatory proteins, which could have additive or synergistic effects on gene expression, or which could act through independent parallel pathways. Guard cell-specific transcription factors, such as the recently identified AtMYB60 and AtMYB61 genes, are good candidates for contributing to the modula- tion of gene expression in stomata (Cominelli et al., 2005; Liang et al., 2005). Clearly, additional work is needed to gain more insight into the cis- and trans-acting mechanisms that direct expression in guard cells. The gene trap lines described in this study provide a valuable starting point for future molecular and bioinformatic analyses.

\section{Experimental procedures}

\section{Plant growth and GUS assays}

All the EXOTIC lines are in the ecotype Landsberg erecta (Ler). Seeds from individual lines were surface-sterilized for $2 \mathrm{~min}$ in $80 \%$ $\mathrm{v} / \mathrm{v}$ ethanol, followed by $5 \mathrm{~min}$ in $3 \% \mathrm{NaClO}$, rinsed with sterile distilled water, and plated on Petri dishes containing Murashige and Skoog medium, $1 \% \mathrm{w} / \mathrm{v}$ sucrose, $0.8 \% \mathrm{w} / \mathrm{v}$ agar and $50 \mu \mathrm{g} \mathrm{ml}^{-1}$ kanamycin. Plants were grown under long-day conditions $(16 \mathrm{~h}$ light $/ 8 \mathrm{~h}$ dark, at $100 \mu \mathrm{mol} \mathrm{m}{ }^{-2} \mathrm{sec}^{-1}$ ) at $22^{\circ} \mathrm{C}$ in a controlled growth chamber. For analysis of GUS expression, tissues were vacuuminfiltrated and incubated at $37^{\circ} \mathrm{C}$ for $6-60 \mathrm{~h}$ in the following staining solution: $50 \mathrm{~mm}$ sodium phosphate buffer, $\mathrm{pH} 7,0.1 \%$ Triton- $\mathrm{X} 100$, $0.5 \mathrm{mg} \mathrm{ml}^{-1} \mathrm{X}$-glucoronic acid and $0.5 \mathrm{~mm}$ FeCN. Tissues were cleared with $70 \%$ ethanol and examined using an Olympus SZX12 stereomicroscope (http://www.olympus-global.com/).

\section{Gene trap insertion site identification}

Chromosomal DNA flanking DsG insertions was amplified by TAIL-PCR, as described at http://www.jic.ac.uk/met/handbook.pdf. hosting/. Multiple PCR reactions were performed on total genomic DNA using a series of DsG nested primers (Ds3-1, ACCCGACCGGATCGTATCGGT; Ds3-2, CGATTACCGTATTTATCCCGTTC; Ds3-4, CCGTCCCGCAAGTTAAATATG) and the adaptor primer AD2 (NGTCGA[G/C][A/T]GANA[A/T]GAA). Insertion sites were confirmed by independent PCR amplifications, using a genespecific primer (Table S1) paired with a DsG primer.

\section{Laser capture microdissection of leaf tissues and RT-PCR analyses}

Leaf tissues from Ler plants were prepared as described previously (Kerk et al., 2003) and microdissected using the Pix-Cell II LCM system (Arcturus Engineering, http://www.arctur.com/). RNA from LCM-harvested cells was prepared using the PicoPure kit (Arcturus Engineering), and reverse-transcribed using Superscript ${ }^{\mathrm{TM}}$ II reverse transcriptase (Invitrogen, http://www.invitrogen.com/). RT-PCRs were performed, amplifying target sequences and control genes for 25 or 40 cycles, using the primers listed in Table S2. PCR products were transferred onto Hybond $\mathrm{N}+$ nylon membranes (Amersham, http://www.amersham.com/), hybridized with gene-specific probes, labelled using the DIG-High Prime kit (Roche, http://www. roche.com).

\section{Bioinformatic analyses}

To estimate the probability of finding by chance a given number of [A/T]AAAG motif occurrences within a region of at most $100 \mathrm{bp}$, the number of occurrences on each strand of Arabidopsis intergenic regions, for oligos AAAAG and TAAAG, was determined. Next, a $P$-value with a hypergeometric distribution was calculated on the 
basis of four parameters: (i) total size of intergenic regions, (ii) AAAAG and TAAAG motif count in intergenic regions, (iii) size of the selected region, and (iv) motif count in the selected region. Only regions containing at least three occurrences of the motif on either strand were considered.

\section{Phenotypic analyses}

Stomatal density and stomatal index were determined in young rosette leaves that had been cleared in $70 \%$ ethanol; the leaves were examined using a stereomicroscope. Four leaf areas of approximately $40 \times 10^{3} \mu \mathrm{m}^{2}$ were examined for each genotype. Toluidine blue staining assays were performed as described previously (Tanaka et al., 2004).

Stomatal aperture measurements were performed on epidermal strips, incubated in $30 \mathrm{~mm} \mathrm{KCl}, 10 \mathrm{~mm}$ MES- $\mathrm{KOH}, \mathrm{pH} 6.5$, at $22^{\circ} \mathrm{C}$, and exposed to light $\left(300 \mu \mathrm{mol} \mathrm{m} \mathrm{mec}^{-1}\right)$ or $5 \mu \mathrm{m} \mathrm{ABA}$ for $3 \mathrm{~h}$. Stomatal apertures were measured using a Nikon Optiphot-2 microscope (http://www.nikon.com/) fitted with a digital camera and a TG 1017 digitizing table (Houston Instruments; http:// www.tms-plotters.com) linked to a personal computer.

\section{Acknowledgements}

The authors thank M. Kater for comments on the manuscript, and the participants of the EXOTIC project for contributing to the generation of the gene trap lines. This work was supported by grants from the European Community Framework 5th Program (QLG2 1999-00351) to M.B. and C.T., and grants from the Italian Ministero dell'Istruzione, dell'Università e della Ricerca-Fondo Investimenti Ricerca di Base (MIUR-FIRB) to C.T.

\section{Supplementary Material}

The following supplementary material is available for this article online:

Figure S1. Insertion site and RT-PCR detection of fusion transcripts in GT1345 and GT105628.

Table S1. Gene-specific primers used in PCR amplifications of the flanking insertion sites.

Table S2. Primers used in RT-PCR analyses of LCM-purified cells This material is available as part of the online article from http:// www.blackwell-synergy.com.

Please note: Blackwell publishing are not responsible for the content or functionality of any supplementary materials supplied by the authors. Any queries (other than missing material) should be directed to the corresponding author for the article.

\section{References}

Allen, G.J., Kuchitsu, K., Chu, S.P., Murata, Y. and Schroeder, J.I. (1999) Arabidopsis abi1-1 and abi2-1 phosphatase mutations reduce abscisic acid-induced cytoplasmic calcium rises in guard cells. Plant Cell, 11, 1785-1798.

Bergmann, D.C. and Sack, F.D. (2007) Stomatal development. Annu. Rev. Plant Biol. 58, 163-181.

Cocherel, S., Perez, P., Degroote, F., Genesteir, S. and Picard, G. (1996) A promoter identified in the $3^{\prime}$ end of the Ac transposon can be activated by cis-acting elements in transgenic Arabidopsis plants. Plant Mol. Biol. 30, 539-551.

Cominelli, E., Galbiati, M., Vavasseur, A., Conti, L., Sala, T., Vuylsteke, M., Leonhardt, N., Dellaporta, S.L. and Tonelli, C. (2005) A guard-cell-specific MYB transcription factor regulates stomatal movements and plant drought tolerance. Curr. Biol. 15, 11961200.

Gosti, F., Beaudoin, N., Serizet, C., Webb, A.A., Vartanian, N. and Giraudat, J. (1999) ABI1 protein phosphatase $2 \mathrm{C}$ is a negative regulator of abscisic acid signaling. Plant Cell, 11, 1897-1910.

Honys, D. and Twell, D. (2004) Transcriptome analysis of haploid male gametophyte development in Arabidopsis. Genome Biol. 5, R85.

Hughes, J.D., Estep, P.W., Tavazoie, S. and Church, G.M. (2000) Computational identification of cis-regulatory elements associated with groups of functionally related genes in Saccharomyces cerevisiae. J. Mol. Biol. 296, 1205-1214.

Kerk, D., Bulgrien, J., Smith, D.W., Barsam, B., Veretnik, S. and Gribskov, M. (2002) The complement of protein phosphatase catalytic subunits encoded in the genome of Arabidopsis. Plant Physiol. 129, 908-925.

Kerk, N.M., Ceserani, T., Tausta, S.L., Sussex, I.M. and Nelson, T.M. (2003) Laser capture microdissection of cells from plant tissues. Plant Physiol. 132, 27-35.

Klein, M., Perfus-Barbeoch, L., Frelet, A., Gaedeke, N., Reinhardt, D., Mueller-Roeber, B., Martinoia, E. and Forestier, C. (2003) The plant multidrug resistance $A B C$ transporter AtMRP5 is involved in guard cell hormonal signalling and water use. Plant J. 33, 119129.

Klein, M., Geisler, M., Suh, S.J. et al. (2004) Disruption of AtMRP4, a guard cell plasma membrane ABCC-type ABC transporter, leads to deregulation of stomatal opening and increased drought susceptibility. Plant J. 39, 219-236.

Leonhardt, N., Kwak, M.J., Robert, N., Waner, D., Leonhardt, G. and Schroeder, J.I. (2004) Microarray expression analyses of Arabid opsis guard cells and isolation of a recessive abscisic acid hypersensitive protein phosphatase $2 \mathrm{C}$ mutant. Plant Cell, 16, 596-615.

Liang, Y.K., Dubos, C., Dodd, I.C., Holroyd, G.H., Hetherington, A.M. and Campbell, M.M. (2005) AtMYB61, an R2R3-MYB transcription factor controlling stomatal aperture in Arabidopsis thaliana. Curr. Biol. 15, 1201-1206.

Liu, Y.G., Mitsukawa, N., Oosumi, T. and Whittier, R.F. (1995) Efficient isolation and mapping of Arabidopsis thaliana T-DNA insert junctions by thermal asymmetric interlaced PCR. Plant J. 8, 457463.

MacRobbie, E.A. (1998) Signal transduction and ion channels in guard cells. Philos. Trans. R Soc. Lond. [B], 353, 1475-1488.

Melotto, M., Underwood, W., Koczan, J., Nomura, K. and He, S.Y. (2006) Plant stomata function in innate immunity against bacterial invasion. Cell, 126, 969-980.

Merlot, S., Gosti, F., Guerrier, D., Vavasseur, A. and Giraudat, J. (2001) The ABI1 and ABI2 protein phosphatases $2 C$ act in a negative feedback regulatory loop of the abscisic acid signalling pathway. Plant J. 25, 295-303.

Nagawa, S., Sawa, S., Sato, S., Kato, T., Tabata, S. and Fukuda, H. (2006) Gene trapping in Arabidopsis reveals genes involved in vascular development. Plant Cell Physiol. 47, 394-405.

Nakamura, R.L., McKendree, W.L. Jr, Hirsch, R.E., Sedbrook, J.C. Gaber, R.F. and Sussman, M.R. (1995) Expression of an Arabidopsis potassium channel gene in guard cells. Plant Physiol. 109, 371-374.

Nakayama, N., Arroyo, J.M., Simorowski, J., May, B., Martienssen, R. and Irish, V.F. (2005) Gene trap lines define domains of gene regulation in Arabidopsis petals and stamens. Plant Cell, 17, 2486-2506.

Paquette, S.M., Bak, S. and Feyereisen, R. (2000) Intron-exon organization and phylogeny in a large superfamily, the para- 
logous cytochrome P450 genes of Arabidopsis thaliana. DNA Cell Biol. 19, 307-317.

Parinov, S., Sevugan, M., Ye, D., Yang, W.C., Kumaran, M. and Sundaresan, V. (1999) Analysis of flanking sequences from dissociation insertion lines: a database for reverse genetics in Arabidopsis. Plant Cell, 11, 2263-2270.

Pei, Z.-M., Ghassemian, M., Kwak, C., McCourt, P. and Schroeder, J. (1998) Role of farnesyltransferase in ABA regulation of guard cell anion channels and plant water loss. Science, 282, 287-290.

Plesch, G., Kamann, E. and Mueller-Roeber, B. (2000) Cloning of regulatory sequences mediating guard cell-specific gene expression. Gene, 249, 83-89.

Plesch, G., Ehrhardt, T. and Mueller-Roeber, B. (2001) Involvement of TAAAG elements suggests a role for Dof transcription factors in guard cell-specific gene expression. Plant J. 28, 455464.

Saez, A., Apostolova, N., Gonzalez-Guzman, M., Gonzalez-Garcia, M., Nicolas, C., Lorenzo, O. and Rodriguez, P. (2004) Gainof-function and loss-of-function phenotypes of the protein phosphatase $2 \mathrm{C}$ HAB1 reveal its role as a negative regulator of abscisic acid signalling. Plant J. 37, 354-369.

Sanchez-Fernandez, R., Davies, T.G.E., Coleman, J.O.D. and Rea, P.A. (2001) The Arabidopsis thaliana ABC protein superfamily, a complete inventory. J. Biol. Chem. 272, 5882-5888.

Schroeder, J.I., Kwak, J.M. and Allen, G.J. (2001) Guard cell abscisic acid signalling and engineering drought hardiness in plants. Nature, 410, 327-333.

Sivanandan, C., Sujatha, T., Prasad, A., Resminath, R., Thakare, D., Bhat, S. and Srinivasan, R. (2005) T-DNA tagging and characterization of a cryptic root-specific promoter in Arabidopsis. Biochim. Biophys. Acta, 1731, 202-208.

Springer, P.S. (2000) Gene traps: tools for plant development and genomics. Plant Cell, 12, 1007-1020.

Stangeland, B., Salehian, Z., Aalen, R., Mandal, A. and Olsen, O.A. (2003) Isolation of GUS marker lines for genes expressed in Arabidopsis endosperm, embryo and maternal tissues. J. Exp. Bot. 54, 279-290.
Sundaresan, V., Springer, P., Volpe, T., Haward, S., Jones, J.D., Dean, C., Ma, H. and Martienssen, R. (1995) Patterns of gene action in plant development revealed by enhancer trap and gene trap transposable elements. Genes Dev. 9, 1797-1810.

Tanaka, T., Tanaka, H., Machida, C., Watanabe, M. and Machida, Y. (2004) A new method for rapid visualization of defects in leaf cuticle reveals five intrinsic pattern of surface defects in Arabidopsis. Plant J. 37, 139-146.

Telfer, A. and Poethig, R.S. (1994) Leaf development in Arabidopsis. In Arabidopsis (Somerville, C.R. and Meyorowitz, M.E., eds). Cold Spring Harbor, NY: Cold Spring Harbor Laboratory Press, pp. 379401.

Tung, C.W., Dwyer, K.G., Nasrallah, M.E. and Nasrallah, J.B. (2005) Genome-wide identification of genes expressed in Arabidopsis pistils specifically along the path of pollen tube growth. Plant Physiol. 138, 977-989.

Van de Brule, S. and Smart, C.C. (2002) The plant PDR family of ABC transporters. Planta, 216, 95-106.

Wellesen, K., Durst, F., Pinot, F., Benveniste, I., Nettesheim, K., Wisman, E., Steiner-Lange, S., Saedler, H. and Yephremov, A. (2001) Functional analysis of the LACERATA gene of Arabidopsis provides evidence for different roles of fatty acid omegahydroxylation in development. Proc. Natl Acad. Sci. USA, 98, 9694-9699.

Xiao, F., Goodwin, S.M., Xiao, Y., Sun, Z., Baker, D., Tang, X., Jenks, M.A. and Zhou, J.M. (2004) Arabidopsis CYP86A2 represses Pseudomonas syringae type III genes and is required for cuticle development. EMBO J. 23, 2903-2913.

Yamada, K. Lim, J., Dale, J.M., et al. (2003) Empirical analysis of transcriptional activity in the Arabidopsis genome. Science, 302, 842-846.

Yanagisawa, S. and Schmidt, R.J. (1999) Diversity and similarity among recognition sequences of Dof transcription factors. Plant J. 17, 209-214.

Zimmermann, P., Hirsch-Hoffmann, M., Hennig, L. and Gruissem, W. (2004) GENEVESTIGATOR. Arabidopsis microarray database and analysis toolbox. Plant Physiol., 136, 2621-2632. 